\title{
Adsorption of Polyesters on Glass, Silica, and Alumina
}

\author{
Robert R. Stromberg, Alan R. Quasius, Samuel D. Toner, and Midgett S. Parker
}

\begin{abstract}
The adsorption of several saturated, linear polyesters has been studied under a variety of conditions. The study also included di- $n$-butyl sebacate as a model low molecular weight ester and poly(methyl methacrylate). The adsorbents were type E glass powder, silica, and alumina. The glass powder and silica were nonporous materials; the alumina contained a large internal pore structure. The rate of adsorption of the polyesters on glass was very rapid and the adsorpt on isotherm was irreversible. Adsorption from a poor solvent was favored over adsorption from a good solvent. A large number of sites are available on the adsorbent for bond formation and the adsorbed polymer most probably extends into the solution in a coiled configuration. Metallic ions, in addition to silicon, appear to be involved in an electrostatic bond between the polymer and the glass. The Langmuir equation is obeyed at high-equilibrium concentrations, although there is nonconformity at the low concentrations.
\end{abstract}

\section{Introduction}

Although the mechanism of adhesion has received attention for a number of years and considerable information has been obtained, no theory has been developed that is sufficiently general to apply to all systems and that will predict the behavior of new systems.

Adhesion between two materials is restricted to an extremely narrow zone which involves a thin portion of each bulk material. Inasmuch as the locus of the interaction between a solid and an adhesive is at the interface, it is apparent that additional knowledge of this interface is required to determine the basic factors involved in adhesion.

One approach to the determination of interfacial properties is a study of the adsorption of polymers onto solid surfaces and a study of the configuration of the polymer at the interface. The adsorption of polymers on solid surfaces is different in many respects from the adsorption of small molecules. The adsorption site and the configuration of an adsorbed small moelcule is usually fixed within known limits. The nature and the adsorbability of the end groups and the "monomer" unit reoccurring along the chain, together with inter- and intramolecular interactions, present a much more complex arrangement for polymer molecules.

The work reported here is principally concerned with the adsorption of saturated linear polyesters onto glass, silica, and alumina. The effects of solvent, chemical structure of the polymers, and temperature were studied.

\section{Materials}

The adsorbents used for this study were glass, silica, and alumina.

The glass was the kind used in the manufacture of glass fibers and is known as "type E". To obtain large surface areas and proper intermixing of

${ }_{1}$ Presented before the Division of Polymer Chemistry of the American Chemical Society at the San Francisco meeting, April 1958.

${ }_{2}$ This work was done, in part, under a project sponsored by the Bureau of Aeronautics, Department of the Navy. the adsorbent with the polymer solution, the glass was prepared in powder form. Type E glass marbles were broken in a "diamond" mortar, and ground in a ball mill containing type $\mathrm{E}$ glass marbles as balls. The powder was sieved through a U. S. standard sieve number 325 with holes of $44 \mu$. A large quantity of glass powder, prepared in this manner, was thoroughly mixed to obtain homogeneity and stored under vacuum in sealed-glass tubes to minimize changes in the surface of the glass.

An electron micrograph of a replica of the surface of this adsorbent is shown in figure 1 . The lined ridges and grooves in the surface are the result of glass fractures that occurred in the mortar where a sharp blow brings about the size reduction. The rough, granular portion was caused by the grinding action in the ball mill. The roughness caused by the grinding contributes to the surface area by a factor of approximately two. The powder was nonporous and had a surface area, determined by nitrogen adsorption and use of the Brunauer, Emmett, Teller (B. E. T.) equation, of $0.68 \mathrm{~m}^{2} / \mathrm{g}$. The chemical analysis of this glass is given in table 1 . The other adsorbents are also listed in this table.

TABLE 1. Adsorbents

\begin{tabular}{|c|c|c|c|}
\hline Material & $\begin{array}{l}\text { Surface } \\
\text { area }\end{array}$ & Particle size & Chemical analysis \\
\hline Silica a ${ }^{a} \ldots$ & $\begin{array}{c}m^{2} / g \\
175 \text { to } 200\end{array}$ & $\begin{array}{c}\mu \\
0.015 \text { to } 0.620\end{array}$ & $\begin{array}{c}w t \% \\
\mathrm{SiO}_{2}, 99.0 \text { to } 99.7 \text {; Free }\end{array}$ \\
\hline Type E glass b & 0.68 & 80 to 200 mesh & $\begin{array}{l}\mathrm{H}_{2} \mathrm{O}, 0.2 \text { to } 2.0 . \\
\mathrm{SiO}_{2}, 55 ; \\
\mathrm{CaO}^{2}, 16.0 \\
\mathrm{Al}_{2} \mathrm{O} \\
\mathrm{B}_{2} \mathrm{O}_{3}, 14.5 \\
\mathrm{MgO}, 5.0\end{array}$ \\
\hline & & & \\
\hline
\end{tabular}

a Information obtained from manufacturer.

b For chemical analysis of type E glass see reference 11.

The silica was a type "prepared in a hot gaseous environment $\left(1,100^{\circ} \mathrm{C}\right)$ by the vapor-phase hydrolysis of a silicon compound." Some of the properties reported by the manufacturer are listed in table 1 . It was noncrystalline and had a surface area deter- 


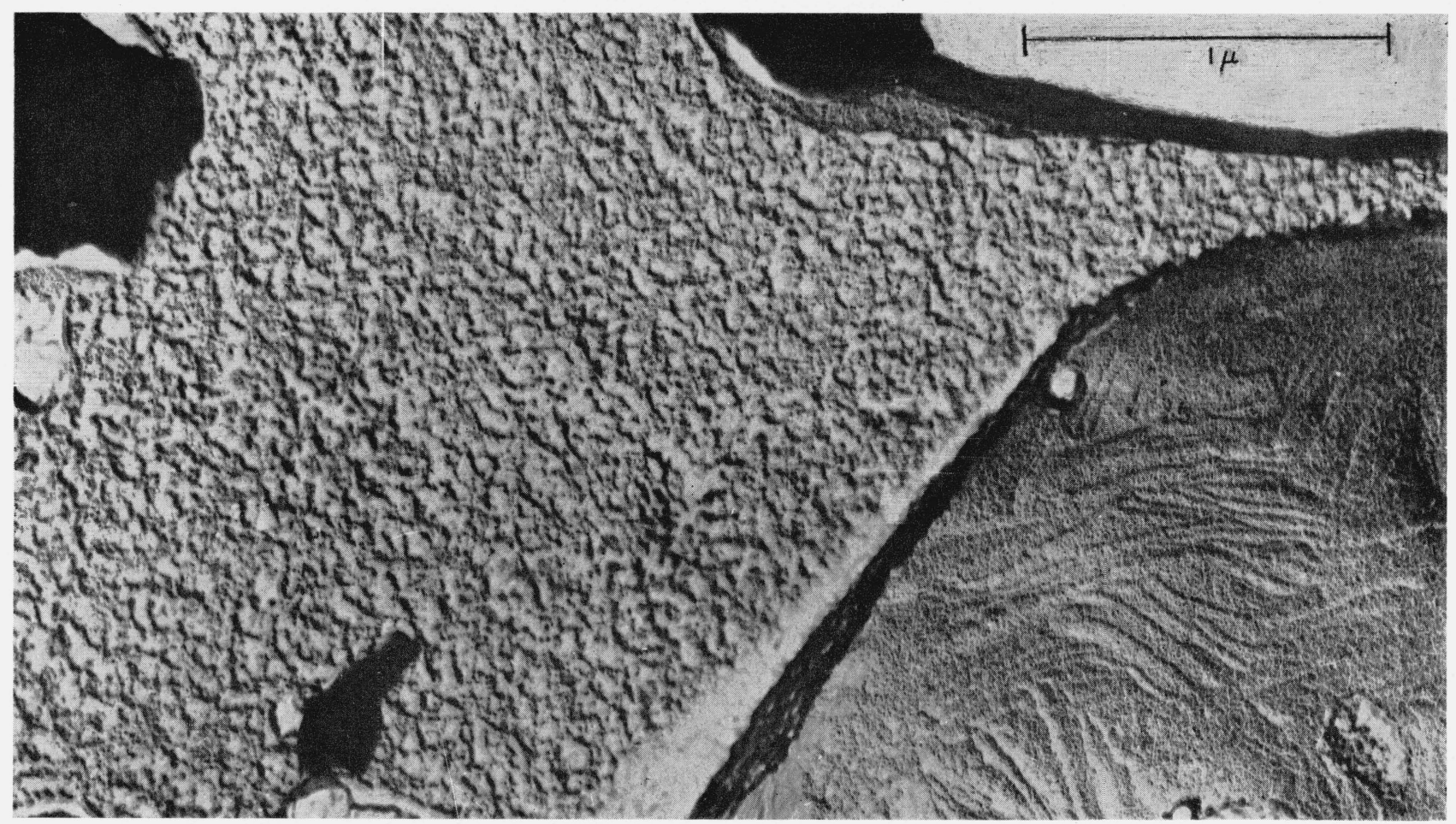

FiguRE 1. Electron micrograph of surface of type E glass particle.

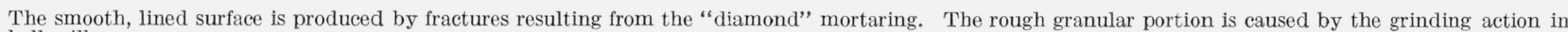
the ball mill.

mined by nitrogen adsorption and electron microscopy of about $190 \mathrm{~m}^{2} / \mathrm{g}$. The agreement between the values obtained by the two techniques indicates that the material was nonporous. The large surface area arises, naturally, from the small particle size. Inasmuch as large surface areas are experimentally easier to handle and adsorption onto nonporous structures is easier to interpret, the silica in this form provided a desirable adsorbent.

The alumina was a type used for chromatographic analysis, and had a B. E. T. surface area of $210 \mathrm{~m}^{2} / \mathrm{g}$. As this alumina had both a large surface area and relatively large particles, it appears that an internalpore structure was associated with the material.

The polymers studied are listed in table 2 . The polyesters were furnished by James Farr of the Thiokol Chemical Corporation. They were prepared by refluxing the glycol and dibasic acid or anhydride for approximately $40 \mathrm{hr}$ at temperatures up to $250^{\circ} \mathrm{C}$ with benzene or xylene added to remove the water of condensation. Following completion of the polymerization the systems were evacuated to remove the benzene or xylene and traces of water. The poly(neopentyl succinate) and poly(pentamethylene succinate) were crystalline materials, and the poly(propylene adipate) and poly(ethylene phthalate) were amorphous.

The poly (methyl methacrylate) was obtained from the Rohm and Haas Company. It had an intrinsic viscosity of 2.66 deciliters per gram in ethylene dichloride at $25^{\circ} \mathrm{C}$ and a calculated viscosity average molecular weight of $1.2 \times 10^{6}$.
Solvents that would permit analysis of the polymer concentration by infrared absorption were required. Also, a comparison of adsorption from good and poor solvents was desired. Toluene was selected as a very poor solvent and chloroform as a good solvent. The solvents were dried by refluxing the toluene over sodium for several hours and by shaking the chloroform over calcium chloride. Both were freshly distilled prior to use.

TABle 2. Polymers

\begin{tabular}{|c|c|c|c|}
\hline & $\overline{\mathrm{M}} \mathrm{n}$ a & \multirow{4}{*}{$\begin{array}{l}\text { Poly (trimethy- } \\
\text { lene adipate) } \\
\text { Poly (pentameth- } \\
\text { ylene succinate) } \\
\text { Poly (ethylene } \\
\text { adipate) } \\
\text { Di-- } n \text {-butyl---- } \\
\text { sebacate...---- } \\
\text { Poly (methyl } \\
\text { methacrvlate) }\end{array}$} & $\overline{\mathrm{M}} \mathrm{n}$ \\
\hline $\begin{array}{l}\text { Poly (neopentyl } \\
\text { succinate) }\end{array}$ & \multirow{3}{*}{$\begin{array}{l}4,400 \\
5,400 \\
2,900\end{array}$} & & 4000 \\
\hline $\begin{array}{l}\text { Poly (propylene } \\
\text { adipate) }\end{array}$ & & & 4,50 \\
\hline $\begin{array}{l}\text { Poly (ethylene } \\
\text { phthalate) }\end{array}$ & & & $\begin{array}{c}3,800 \\
(314.4) \\
1.2 \times 10^{6}\left(\overline{\mathrm{M}}_{\eta}\right) \mathrm{b}\end{array}$ \\
\hline
\end{tabular}

a $\bar{M} n$, Number average molecular weight

b $\overline{\mathrm{M}}_{\eta}$, Viscosity average molecular weight.

\section{Procedure}

The amount of material adsorbed was determined by measuring the change in concentration of the polymer after equilibration of the solution. The concentration changes in the polyester solutions were measured by changes in the carbonyl absorption at approximately $5.8 \mu$. A double-beam infrared spec- 
trophotometer was used for these analyses. A cell length of $0.4 \mathrm{~mm}$ was used and the polymer solutions were compensated with solvent in the reference beam. A separate calibration curve, based on at least six polymer concentrations, was obtained for each experiment. The sensitivity was such that a change in absorbance of approximately 0.2 was obtained for each concentration change of $1 \mathrm{mg} / \mathrm{ml}$. An experiment usually employed sufficient adsorption tubes to complete one isotherm.

The poly(methyl methacrylate) solutions were analyzed for polymer concentration by a nephelometric technique [1]. ${ }^{3}$ The polymer was precipitated from solution as a colloidal suspension by the dropwise addition, with constant stirring, of $10 \mathrm{ml}$ of a butanol-methanol mixture $(2: 1)$ to $2 \mathrm{ml}$ of polymer solution. The amount of light scattered at $90^{\circ}$ by this suspension was measured with a light-scattering microphotometer. A rigid time schedule was followed for the entire procedure. This made possible reproducible results. During the measurement of the turbidity the stirring was discontinued. The concentration of polymer was determined from calibration curves.

The adsorption was carried out for most experiments with $20 \mathrm{ml}$ of polymer solution and either $10 \mathrm{~g}$ of glass powder, $5 \mathrm{~g}$ of alumina, or $1 \mathrm{~g}$ of silica. After adjusting the adsorbent and polymer solution to the required temperature separately, for most cases the solution was mixed with the adsorbent, the Pyrex tube rapidly heated with a torch, sealed, and the adsorbent-polymer solution mixture rotated at approximately $9 \mathrm{rpm}$ in a constant-temperature bath. In some cases the glass powder had been heated to $350^{\circ} \mathrm{C}$ in vacuum for $24 \mathrm{hr}$ prior to addition of the polymer solution. These outgassed and heat-treated samples were mixed with polymer solutions, both without any contact with the air and after exposure to air. The solution-adsorbent mixtures were usually rotated for approximately $20 \mathrm{hr}$. Following the adsorption period the tubes were centrifuged and the solution removed for analysis.

For desorption studies appropriate quantities of solution were removed after adsorption and pure solvent added to the tubes which were then resealed and rotated at constant temperature for 2 to 3 days. The supernatant solutions were then analyzed for polymer concentration.

\section{Results and Discussions}

\subsection{General Shape of Isotherms}

The adsorption isotherm of poly(methyl methacrylate) from toluene solution onto type $\mathrm{E}$ glass powder is shown in figure 2 . The shape of the curve is similar to that obtained by Jenckel and Rumbach [1] for this polymer on aluminum powder, quartz, and glass wool. There is no appreciable change in the quantity of polymer adsorbed after an equilibrium concentration of approximately $0.1 \mathrm{mg} / \mathrm{ml}$ has been reached. This rapid attainment of a plateau at

\footnotetext{
3 Figures in brackets indicate the literature references at the end of this paper.
}

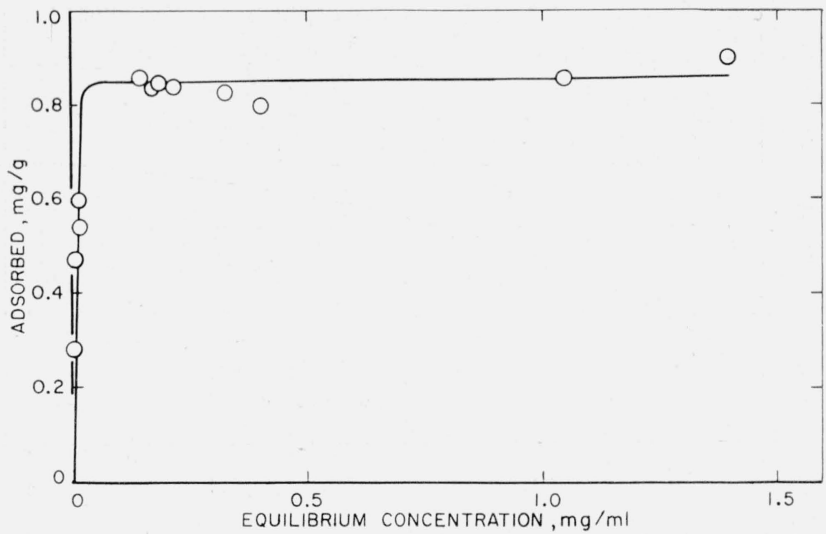

FIGURE 2. Adsorption of poly(methyl methacrylate) from toluene on type E glass at $30^{\circ} \mathrm{C}$.

low-equilibrium concentrations has also been reported by Koral, Ullman, and Eirich [2] for the adsorption of poly(vinyl acetate) on iron and tin powder. The adsorption sites are readily occupied by the polymer at low-solution concentrations. In the competition between the adsorbent and solvent for polymer, the adsorbent has a strong affinity for the polymer and the poly(methyl methacrylate) molecules are held to the adsorbent until active sites are no longer available. In the case of poly (methyl methacrylate) the nature of the adsorption isotherm appears to be independent of the adsorbent, at least for surfaces so far investigated.

The polyesters studied yielded adsorption isotherms quite different from those of poly(methyl methacrylate). Isotherms obtained at $30^{\circ} \mathrm{C}$ for the adsorption from chloroform and toluene solutions of several polyesters onto type $\mathrm{E}$ glass powder are given in figure 3 . The polyester isotherms do not level off into a plateau as was the case with poly(methyl methacrylate). The quantity of polymer adsorbed continues to increase at the highersolution concentrations. This type of isotherm is in agreement with a statistical theory of polymer adsorption developed by Simha, Frisch, and Eirich

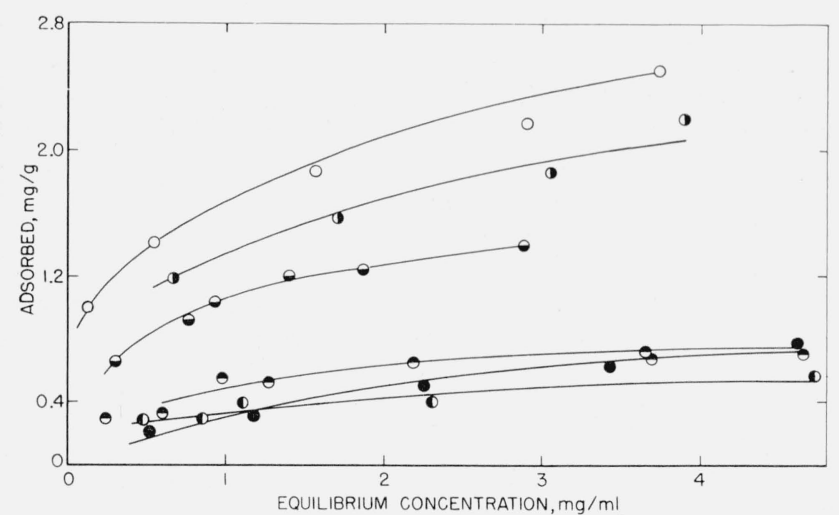

Figure 3. Adsorption of several polyesters on type $E$ glass at $30^{\circ} \mathrm{C}$.

Adsorption from toluene: $\bigcirc$, Poly (trimethylene adipate); poly (pentamethyl ene succinate); $\boldsymbol{\Theta}$, poly (propylene adipate).

Adsorption from chloroform: $\boldsymbol{\odot}$, Poly(pentamethylene succinate); $\mathbf{0}$, poly (ethylene phthalate); , poly (ethylene adipate). 


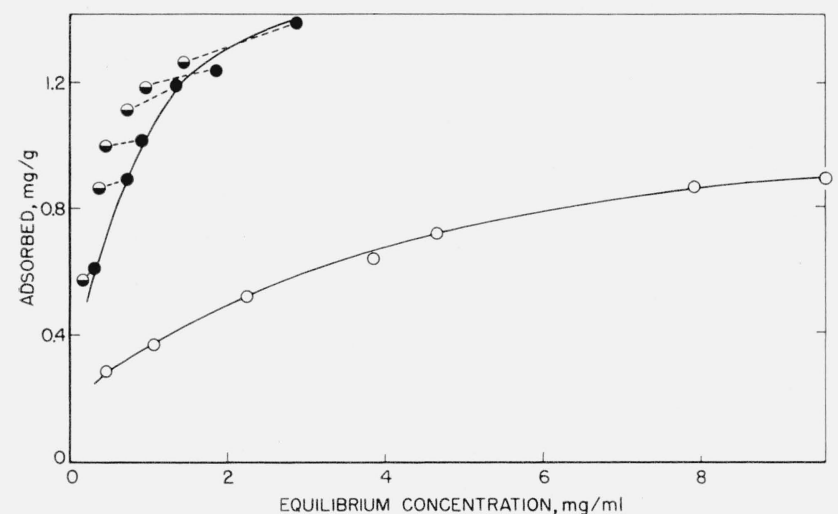

Figure 4. Adsorption isotherm on type $E$ glass and desorption of polymer at $30^{\circ} \mathrm{C}$. , Adsorption of poly (trimethylene adipate) from chloroform; 9 , adsorption
of poly(propylene adipate) from toluene; $\Theta$, desorption of poly (propylene adipate) with toluene.

[3 to 6 ], which predicts an initial steep rise and a very slow attainment of the asymptotic limit. The theory was primarily developed for low-surface coverage. As saturation has not been attained, even at concentrations as high as $10 \mathrm{mg} / \mathrm{ml}$, as shown in figure 4 , some of the polyester isotherms at the lower equilibrium solution concentrations may be in this low-surface coverage range. In the case of poly (methyl methacrylate), that position of the isotherm which corresponds to little surface coverage exists only at very dilute solution concentrations, which are experimentally difficult to measure.

\subsection{Dependence on Solvent and Water}

The quantity of material adsorbed was very dependent on the solvent and about 2 to 4 times as much polymer was adsorbed from the extremely poor solvent, toluene, as from the good solvent, chloroform. This solvent dependence is, in part, the result of competition between solvent and adsorbent for the polymer and the greater adsorption from the poor solvent is in agreement with the theoretical treatment [3 to 6$]$. The curves shown in figure 3, obtained from the same solvent are all similar in shape, although the spread among the curves obtained from the toluene solutions is considerably greater than those obtained from chloroform solutions.

Measurements for varying periods of time demonstrated that the adsorption of the polyesters onto the type E glass powder was very rapid, reaching its equilibrium value within 15 sec, which was the shortest time interval studied. Poly(vinyl acetate) has also been reported [2] to adsorb in short time intervals (within an hour) on nonporous surfaces. Diffusion of the bulky polymer mass does not appear to be a major factor in adsorption onto such surfaces. Adsorption in porous networks presents additional problems relating to the ability of the polymer molecule to enter small pores and the availability of large portions of the surface area to such molecules. This will be discussed later.

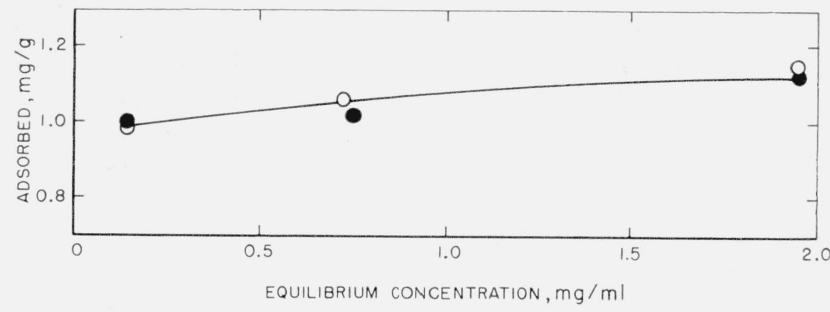

Figure 5. Adsorption of poly(ethylene adipate) from toluene on type E glass at $30^{\circ} \mathrm{C}$.

$\mathrm{O}$, Glass heat cleaned at $350^{\circ} \mathrm{C}$ in vacuum prior to adsorption; pretreated prior to adsorption.

No significant difference in the quantity of polymer adsorbed as a result of a pretreatment of the glass by heating in vacuum at $350^{\circ} \mathrm{C}$ for $24 \mathrm{hr}$ was measured. The results of one such experiment are shown in figure 5 for the adsorption of poly (ethylene adipate) from toluene. Traces of water were undoubtedly still present at the glass surface and it appears that, above these trace quantities, water does not play a significant role in the adsorption of polyesters.

\subsection{Reversibility of Adsorption and Dependence on Temperature}

Although relatively high equilibrium concentrations were required for maximum adsorption of the polyesters, the adsorbed materials were tightly bound to the surface. This is shown by the results of desorption experiments on poly (propylene adipate) in figure 4 and poly(neopentyl succinate) in figure 6 . The irreversibility of adsorption is shown at several concentrations on the isotherm in figure 4 . In the case of poly(neopentyl succinate) only those samples containing the maximum quantity of polymer adsorbed in that experiment were used for desorption. No significant quantity of polymer was desorbed from the glass for either polyester.

After adsorption of poly (neopentyl succinate) onto glass from toluene solution, dilution with chloroform brought about the desorption of an appreciable

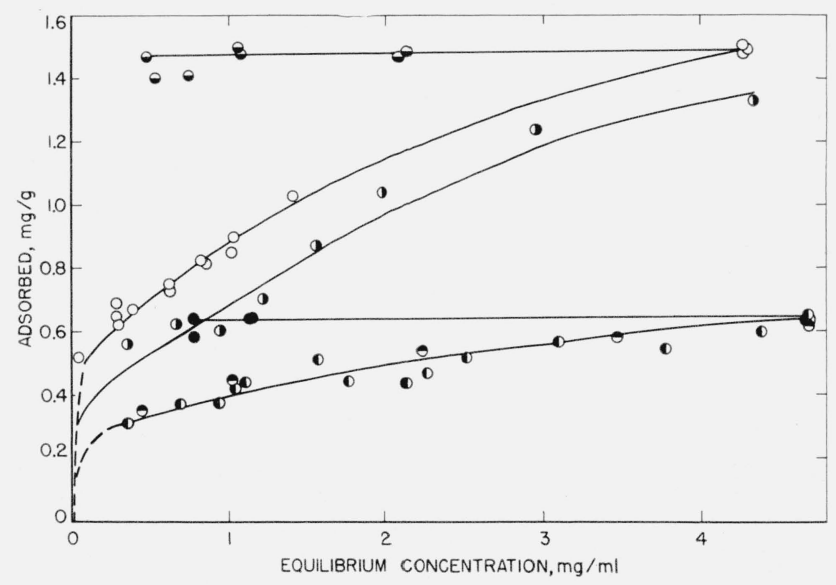

Figure 6. Adsorption and desorption of poly(neopentyl succinate) on type E glass.

, Adsorption from toluene at $30^{\circ} \mathrm{C}$; $\ominus$, desorption at $30^{\circ} \mathrm{C}$ with toluene , adsorption from toluene at $86.8^{\circ} \mathrm{C}$; , adsorption from chloroform at $30^{\circ} \mathrm{C}$; , desorption at $30^{\circ} \mathrm{C}$ with chloroform;, , adsorption from chloroform at $50^{\circ} \mathrm{C}$. 
quantity of polymer. This desorption with the better solvent indicates that the bonds between the polymer and glass are more physical than chemical.

The effect of temperature on the adsorption of poly(neopentyl succinate) is also shown in figure 6 . There was no significant difference in the adsorption from chloroform solution in the temperature range $30^{\circ}$ to $50^{\circ} \mathrm{C}$ and only one curve is drawn through the points obtained at both temperatures. A negative change in adsorption with temperature was observed when toluene was used as the solvent. Both positive-temperature coefficients [2] and positive and negative coefficients [1] have been reported. It is possible that the decrease in the amount of poly(neopentyl succinate) adsorbed at the higher temperature may be a result of increased solubility of the polymer in the poor solvent.

\subsection{Adsorption on Silica and Alumina}

Considerably more polymer was adsorbed per gram of silica or alumina than per gram of glass powder. The adsorption onto silica from chloroform solution for poly(pentamethylene succinate) and poly (neopentyl succinate) is shown in figure 7 . The shape of the isotherm on silica is similar to that obtained on type E glass for polyesters. For the poly(neopentyl succinate) a plateau region had not been reached at concentrations as high as $15 \mathrm{mg} / \mathrm{ml}$.

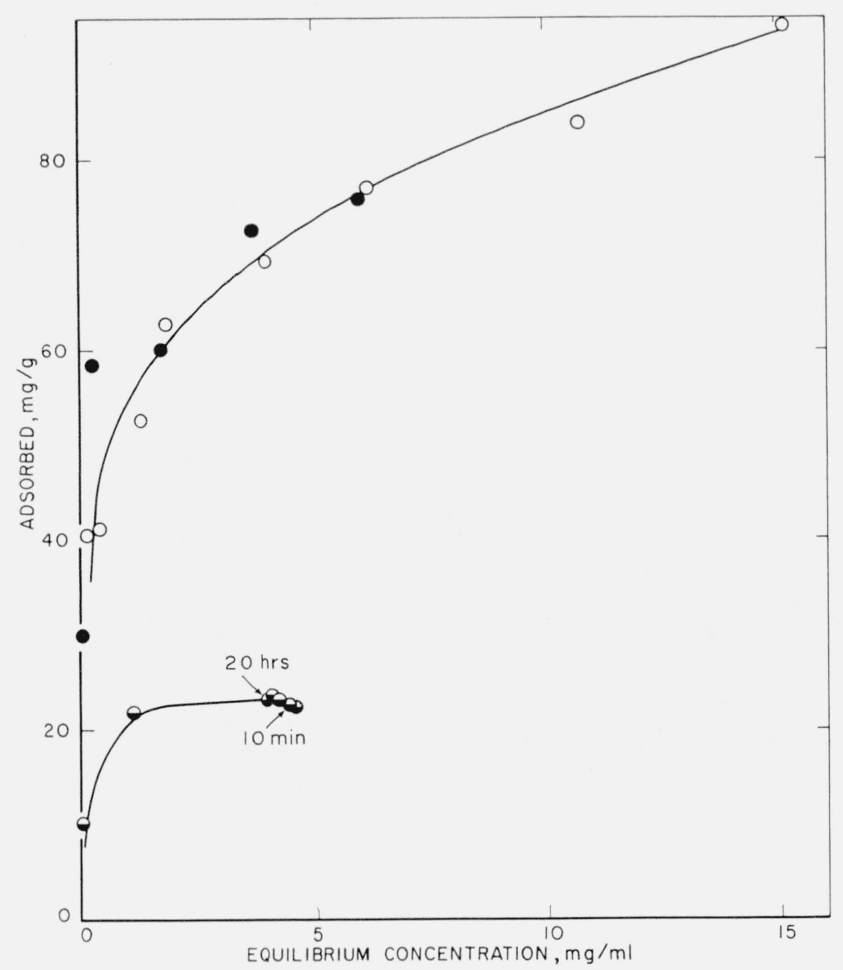

FiguRE 7. Adsorption on silica and alumina from chloroform at $30^{\circ} \mathrm{C}$.

Poly (neopentyl succinate) on silica; poly(pentamethylene succinate)

on silica; , poly (neopentyl succinate) on alumina. were obtained over a time period of $10 \mathrm{~min}$ to $20 \mathrm{hr}$. Virtually no change in adsorption occurred during this interval.
Although the silica and alumina both had approximately the same surface area, about three times the amount of polymer is adsorbed on the silica as is adsorbed on the alumina. The general shape of the curve on alumina, as seen in figure 7 , is different from that obtained for polyesters on the type E glass and silica, and similar to that obtained for poly (methyl methacrylate). The group of points at $4 \mathrm{mg} / \mathrm{ml}$ in figure 7 was obtained from a set of measurements in which the adsorption time was varied from 10 min to $20 \mathrm{hr}$. The porous alumina probably contained areas that are accessible only through pores that were too small to permit access by large polymer molecules. If appreciable portions of the internal surface area were available to the large polymer molecules, the rate of adsorption should have been considerably slower than that indicated in figure 7 . A slow rate of adsorption into the porous network of charcoal has been reported by Hobden and Jellinek [7] and Claesson and Claesson [8]. It appears, therefore, that the internal surface area of the alumina was unavailable to the polymer.

The quantity of polymer adsorbed per unit of surface area is shown in figure 8 for poly(neopentyl succinate) for the adsorbents studied. A much greater surface coverage was achieved on the glass than on the silica or alumina. The small quantity adsorbed on porous alumina is similar to the relatively low quantities of polymer adsorbed on charcoal relative to nonporous adsorbents [1]. It is also possible that the polymer with sufficient time (months) might diffuse into the pores.

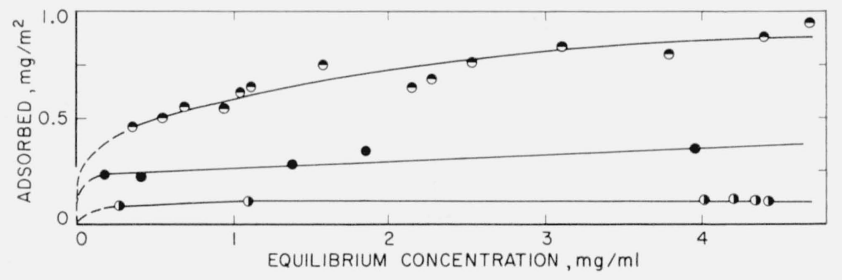

FIGURE 8. Adsorption of poly(neopentyl succinate) on several adsorbents from chloroform at $30^{\circ} \mathrm{C}$.

Adsorption on type $E$ glass; - adsorption on silica; adsorption on alumina.

In addition to silica, type E glass con tains calcium, aluminum, boron, and magnesium oxides. Inasmuch as considerably larger quantities of polymer were adsorbed on the glass relative to the other adsorbents it appears that the positively charged metallic ions, in addition to silicon, present in the surface of the glass have some advantages for bond formation, probably with the oxygen of the ester group. This bond is probably electrostatic in nature. If the results reported by Jenckel and Rumbach [1] are calculated as a function of surface area, a considerably larger quantity of poly(methyl methacrylate) was adsorbed on aluminum powder, which they report was most likely alumina on the surface, than on glass or silica. The amount adsorbed on glass was slightly more than on silica. These results can also be interpreted as indicating the importance of surface atoms such as aluminum for the formation of bonds with the adsorbed polymer. 


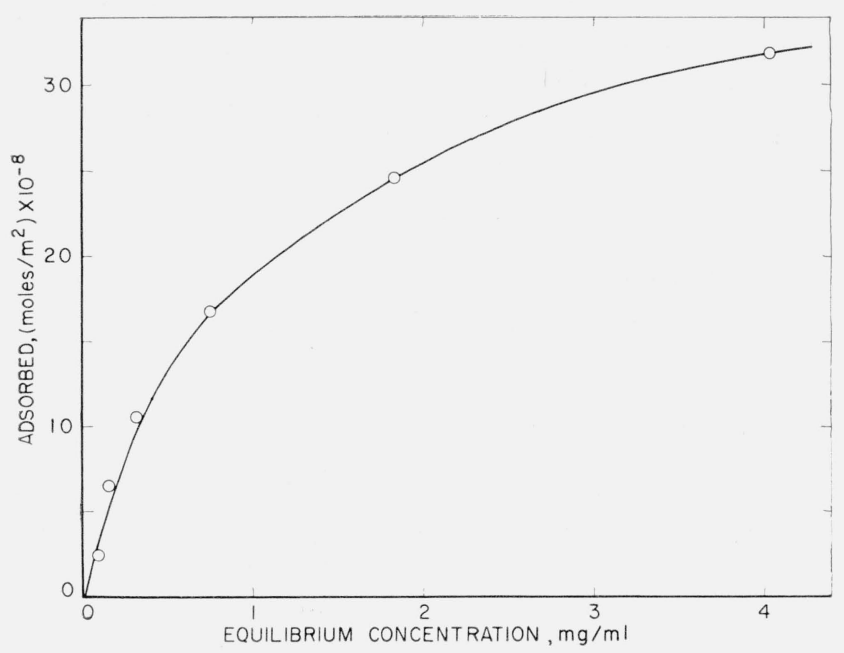

Figure 9. Adsorption of di-n-butyl sebacate on silica from toluene at $30^{\circ} \mathrm{C}$

To determine how a very low molecular weight material with structure similar to the polyesters would behave, the adsorption of di-n-butyl sebacate onto type $\mathrm{E}$ glass and silica was attempted. No adsorption was observed on the glass, using the techniques described earlier. An isotherm was obtained from toluene solution onto silica, however, and is given in figure 9. The shape of the curve is typical for the adsorption of polyesters, although the weight adsorbed was considerably less than that obtained with the polymers. No di-n-butyl sebacate was adsorbed from chloroform solution.

Ellerstein and Ullman [9] reported very small or no adsorption of a linear dimer on glass and attributed this to the small entropy change, $\Delta S$, that would occur upon adsorption of the dimer compared with the much larger change accompanying adsorption of a polymer. The adsorption of the small molecule would only release one solvent molecule into the solution while the adsorption of a polymer molecule on several sites would release several. If there is no appreciable difference in the heat of adsorption, $\Delta H$, for the dimer molecule compared to the polymer molecule, it is possible that this difference in $\Delta S$ accompanying the adsorption process could cause a positive free energy change, $\Delta F$, for the dimer and a negative $\Delta F$ for the polymer. If the configuration of the di-n-butyl sebacate in toluene is such that adsorption at more than one site occurs, permitting a larger entropy change, a negative free energy of adsorption may result, again assuming no change in $\Delta H$. A more open structure in chloroform may permit adsorption at only one site with no advantageous change in the number of degrees of freedom and, consequently, no appreciable adsorption.

The availability of sufficient surface area for the di-n-butyl sebacate molecule to lie flat can be determined from the isotherm for this material. If it is assumed (from a Fisher-Hirschfelder model) that the area occupied per molecule is $620 \mathrm{~A}^{2}$, then at the equilibrium concentration of $1 \mathrm{mg} / \mathrm{ml}$, approximately $1.1 \times 10^{13}$ molecules $/ \mathrm{cm}^{2}$ were adsorbed and would occupy about 70 percent of the available area if they were flat on the surface. At saturation, which is assumed to be approximately $35 \times 10^{-8} \mathrm{moles} / \mathrm{m}^{2}$, $2.1 \times 10^{13}$ molecules $/ \mathrm{cm}^{2}$ were adsorbed and would occupy 130 percent of the surface, indicating that a portion of the molecule extended into the solution, at least at this concentration.

\subsection{Configuration of Adsorbed Molecules}

The deposition of adsorbed polymer in sequences separated by bridges was suggested by Jenckel and Rumbach [1] and an isotherm based on this concept has been derived by Simha, Frisch, and Eirich [3 to 6]. In the case of di-n-butyl sebacate, loops may not occur, although sections of the molecule undoubtedly extend into the solution in a manner similar to the beginning of bridges in polymers. If the molecule is adsorbed at only one location, some indication of the number of available sites can be determined, in this case sites sufficient for at least $2.1 \times 10^{13}$ molecules $/ \mathrm{cm}^{2}$.

The solvent and temperature dependence of the adsorption of polyesters can be explained in part by differences in solubility and in part by differences in the configuration of the polymer molecule. The decrease in free energy that occurs with adsorption is dependent on the solubility of the adsorbate. An increase in solubility as a result of either better solvent or increase in temperature would bring about a decrease in adsorption. In addition, the polymer chain probably exists as a coil with a radius of grration that increases, within limits, with increased solubility. The increase in size of the polymer coil would also result in a decrease in adsorption.

If the adsorbed polymers were to lie flat on the surface, the number of layers can be calculated. The area of a "segment" of poly(neopentyl succinate) is approximately $70 \mathrm{~A}^{2}$. On the glass adsorbent there would be about 5 layers after adsorption from toluene and approximately 2.2 layers from chloroform solution. There would be about a monolayer of this polymer adsorbed on silica and only 0.2 of a layer on alumina after adsorption from chloroform solution.

Attempts to fit the data to the simple adsorption equations of Freundlich and Langmuir were made. The Freundlich equation was obeyed over the greater portion of the concentration range studied, but deviated at both high- and low-solution concentrations. The Langmuir equation was obeyed for poly (methyl methacrylate), except for the very low concentration range. There was marked deviation at concentrations lower than $1 \mathrm{mg} / \mathrm{ml}$ for the polyesters. The Langmuir equation is derived for rigid molecules where the rate of adsorption is in equilibrium with the rate of desorption, and would not necessarily be expected to apply to polymer adsorption, especially the irreversible adsorption of poyesters to glass. Therefore, the deviation for the poly(methyl methacrylate) and the polyesters. is not surprising.

The theory developed by Simha, Frisch, and Eirich [3 to 6] predicts that a high surface coverage 
where there is interference among the polvmer segments, the derived isotherm approaches the Langmuir isotherm [2]. Both the polyesters and poly(methyl methacrylate) appear to obey the Langmuir equation at the higher surface coverage. 'The polyesters depart from linearity at higher solution concentrations than the poly (methyl methacrylate). This may be a result of the more gradual approach to total-surface coverage for the polyesters where concentrations as high as 1 to $2 \mathrm{mg} / \mathrm{ml}$ are required before large-surface coverage and polymer segment interference is obtained. Koral, Ullman, and Eirich [2] found that the adsorption of poly (vinyl acetate) also appears to obey the Langmuir equation in the high-concentration range. Hobden and Jellinek [7] and Jellinek and Northey [10] reported that the adsorption isotherms of polystyrene on charcoal obeyed the Langmuir equation very well over the entire range they studied.

\section{Summary}

To summarize the significance of the adsorption data, it has been shown that the adsorption of polyesters onto glass is very rapid and that strong bonds, probably electrostatic in character, are formed between polyester and glass. This is demonstrated by the irreversibility of the adsorption and the larger quantities of polymer adsorbed on the glass compared to the silica. The adsorption from toluene, a poor solvent, is favored over adsorption from chloroform, a good solvent. This, together with the large number of sites available for bond formation, indicates that the configuration and the radius of gyration of the polymer molecule in solution is an important consideration in determining the quantity of polymer that will occupy a given surface area. The number of layers of polymer that would be adsorbed on the surface of the substrate would be of the order of 2 to 5 in this study if the molecule were to lie flat. As such an arrangement would assume very large alterations in molecular configuration upon adsorption, it is reasonable to assume that the molecule must exist as a coil which extends out into the solution, contacting the surface at several points. This coiled molecule, therefore, also provides opportunity for intermolecular interaction and entanglement during the adsorption process.

The authors are especially indebted to M. Kathryn Wharton who conducted the majority of the infrared analyses. They also express their appreciation to Frank Reinhart, Sanford Newman, Bernard Achhammer, and to Robert Ullman (Polytechnic Institute of Brooklyn) for helpful discussions during the course of the work. The surface area measurements were made by Charles M. Hunt and the electron micrograph by Dr. Newman.

\section{References}

[1] E. Jenckel and B. Rumbach, Z. Elektrochem. 55, 612 (1951).

[2] J. Koral, R. Ullman, and F. R. Eirich, J. Phys. Chem.62, 541 (1958).

[3] R. Simha, H. L. Frisch, and F. R. Eirich, J. Phys. Chem. 5\%, 584 (1953).

[4] H. L. Frisch and R. Simha, J. Phys. Chem. 58, 507 (1954).

[5] H. L. Frisch, J. Phys. Chem. 59, 633 (1955)

[6] H. L. Frisch and R. Simha, J. Chem. Phys. 27, 702 (1957).

[7] J. F. Hobden and H. H. G. Jellinek, J. Polymer Sci. 11, 365 (1953).

[8] I. Claesson and S. Claesson, Arkiv Kemi, Mineral. Geol. [A] 19, (1944).

[9] S. Ellerstein and R. Ullman, Adsorption of poly (methyl methacrylate) on solid surfaces (presented at American Chemical Society Meeting, San Francisco, Calif., A pril 15, 1958.)

[10] H. H. G. Jellinek and H. L. Northey, J. Polymer Sci. 14, 583 (1954).

[11] M. J. O'Leary and D. Hubbard, J. Research NBS 55, 1 (1955) RP2599.

Washington, October 13, 1958. 